\title{
The neostriatum: two entities, one structure?
}

\author{
Violeta G. Lopez-Huerta • Yoko Nakano • Johannes Bausenwein • \\ Omar Jaidar • Michael Lazarus • Yoan Cherassse • Marianela Garcia-Munoz • \\ Gordon Arbuthnott
}

Received: 10 December 2014/ Accepted: 28 January 2015/Published online: 5 February 2015

(C) The Author(s) 2015. This article is published with open access at Springerlink.com

\begin{abstract}
The striosome (or patch) was first identified with anatomical techniques as neurons organized in a three-dimensional labyrinth inserted in and interdigitating the rest of neostriatum: the matrix. Striosome and matrix rapidly became known as two neuronal compartments expressing different biochemical markers, embryonic development and afferent and efferent connectivity. In spite of extensive intrinsic neuronal axonal and dendritic extensions supposed to exchange information between matrix and striosomes, evidence suggested the presence of independent areas. Here, we report that indeed these two areas do not exchange synaptic information. We used genetic
\end{abstract}

Electronic supplementary material The online version of this article (doi:10.1007/s00429-015-1000-4) contains supplementary material, which is available to authorized users.

V. G. Lopez-Huerta · Y. Nakano · J. Bausenwein · O. Jaidar ·

M. Garcia-Munoz · G. Arbuthnott ( $\square)$

Brain Mechanisms for Behavior Unit, Okinawa Institute of

Science and Technology Graduate University, 1919-1 Tancha,

Onna-Son, Kunigami Gun, Okinawa 904-0412, Japan

e-mail: gordon@oist.jp

V. G. Lopez-Huerta

e-mail: violeta@oist.jp

Y. Nakano

e-mail: yoko.nakano@oist.jp

J. Bausenwein

e-mail: bausenwein@gmail.com

O. Jaidar

e-mail: ojaidar@oist.jp

M. Garcia-Munoz

e-mail: marianela@oist.jp

M. Lazarus · Y. Cherassse

University of Tsukuba, Ibaraki 305-0006, Japan

e-mail: lazarus.michael.ka@u.tsukuba.ac.jp expression of channel rhodopsin 2 carried by adeno-associated virus serotype 10 (AAVrh10) that only expresses in neurons of the matrix compartment. Whole-cell patchclamp recordings of matrix neurons activated by light pulses consistently produced inhibitory postsynaptic currents (IPSCs), but the same manipulation did not evoke IPSCs in striosome neurons. The matrix contains both direct and indirect striatal output pathways. By targeting striatal matrix expression of designer receptors exclusively activated by a designer drug (DREADD) hM3di carried by AAVrh10, we were able to inhibit the matrix neuronal compartment of the dorsolateral striatum during performance of a learned single-pellet reach-to-grasp task. As expected, inhibition of matrix neurons by systemic administration of DREADD agonist clozapine- $n$-oxide interfered with performance of the learned task.

Keywords Adeno-associated virus - Limbic system · Reach-to-grasp · Neuromodulation · Volume transmission · Dopamine

\section{Introduction}

Circumscribed "islands of dopamine terminals" scattered in striatum (Olson et al. 1972) became the matrix and striosome (or patch) compartments described in the literature later (Pert et al. 1976; Herkenham and Pert 1981; Graybiel and Ragsdale 1978). They were anatomical curiosities: a large area of neostriatum with neurons of high acetylcholine esterase activity (AChE) (matrix) containing zones poorly stained for AChE (striosomes). As research progressed, the two compartments were observed in primate and non-primate species (Graybiel and Ragsdale 1978; Herkenham and Pert 1981; Wilson et al. 1987) and 
striosomes became the three-dimensional serpentine tube or labyrinth with finger-like branches (Groves et al. 1988; Desban et al. 1993; Mikula et al. 2009; Manley et al. 1994; Breuer et al. 2005) distinguished by their exclusive label to $\mu$ opiate receptor ligands (e.g., MOR1 and naloxone) (Herkenham and Pert 1981) and high enkephalin-like immunoreactivity (Graybiel et al. 1981).

Neurons of the matrix compartment make up about $80 \%$ of striatal volume (Johnston et al. 1990; GimenezAmaya and Graybiel 1991; Mikula et al. 2009) and are rich in calbindin (Gerfen et al. 1985; Kawaguchi et al. 1989; Liu and Graybiel 1992). These neurons develop and migrate later in development than neurons in striosomes (Graybiel et al. 1981; Gerfen et al. 1987a; van der Kooy and Fishell 1987). Inputs to matrix originate in sensory and motor cortical areas (mainly layer V) (Gerfen 1984; Donoghue and Herkenham 1986; Flaherty and Graybiel 1991, 1993; Kincaid and Wilson 1996), prefrontal areas (Eblen and Graybiel 1995), parafascicular and centromedial thalamic nuclei (Herkenham and Pert 1981; Ragsdale and Graybiel 1991) and dorsal substantia nigra compacta (Gerfen et al. 1987b; Prensa and Parent 2001). Outputs project in two directions: to substantia nigra pars reticulata (direct pathway) and to globus pallidus (indirect pathway) (Gerfen 1984; Gerfen et al. 1985; Graybiel et al. 1979; Jimenez-Castellanos and Graybiel 1989; Kawaguchi et al. 1990). Consistent with its input-output patterns, movement-related increases in neuronal activity observed in freely moving rats are located in the matrix compartment (Heidenreich et al. 1994; Brown et al. 2002; Trytek et al. 1996).

Neuronal development and dopamine innervation occur earlier in striosomes than matrix (Graybiel et al. 1981; Gerfen et al. 1987a; van der Kooy and Fishell 1987; Seiger and Olson 1973). Inputs to striosomes are from prelimbic cortex (layers Vb and VI) (Gerfen 1984; Donoghue and Herkenham 1986; Kincaid and Wilson 1996), motor and somatosensory areas (Gerfen 1989), midline thalamic nuclei (paraventricular and rhomboid) (Ragsdale and Graybiel 1991) and neurons located in ventral substantia nigra compacta and substantia nigra pars reticulata (Gerfen et al. 1987b; Prensa and Parent 2001; Tokuno et al. 2002).

Although characterized by their $\mu$ opioid receptors, striosome neurons also express among others dopamine D1 or D2 receptors (Ambrose et al. 2004; Georges et al. 1999; Guttenberg et al. 1996). Outputs from these neurons are to substantia nigra pars compacta (Gerfen et al. 1987b; Watabe-Uchida et al. 2012), to a densocellular zone also poorly stained for AChE (Jimenez-Castellanos and Graybiel 1989). Striosomes provide a reciprocal loop with substantia nigra compacta to control dopamine release and reward-related calculations (Crittenden and Graybiel
2011). Consistent with a reward-related function, striosome neurons release endogenous enkephalin in response to chocolate eating (DiFeliceantonio et al. 2012) and rats learn to self-stimulate when electrodes are located in striosomes (White and Hiroi 1998). Still related to a limbic influence on behavior, mice with a selective striosome lesion were not able to perform in a rotarod task that involves a combination of motor coordination and control of fear of falling (Lawhorn et al. 2009).

In spite of great advances, there are still very important questions to answer regarding matrix and striosome compartments: (1) Do neurons located in striosomes and matrix talk to each other? (2) Can animals perform a learned task with an inhibited matrix compartment? Fortuitously, we found that the adenosine-associated virus (AAV) serotype rh10 infects neurons in the matrix, but not in the striosome compartment. This finding allowed us genetic expression of channel rhodopsin 2 (ChR2) or targeted expression of designer receptors exclusively activated by a designer drug (DREADD) hM3di carried by AAVrh10. Using these techniques, our results suggest that "no" is the likely answer to both questions.

\section{Materials and methods}

\section{Animals}

All our experiments complied with guiding policies and principles for experimental procedures endorsed by the government of Japan and supervised by the local Animal Care and Use Committee.

We used the following mice strains: wild-type c57BL/ $6 \mathrm{~N}$ mice, Swiss Webster bacterial artificial chromosome (BAC) transgenic mice D1-eGFP or D2-eGFP, and D1cCre transgenic lines. Animals were postnatal 25-30 days of either sex for electrophysiological experiments and males only for behavioral experiments.

Adenovirus (AAV) functionally expressed in mouse striatum

We used the following adeno-associated virus (AAV): AAV1-dflox-hChR2-mCherry (Cre-activated, Addgene 20297, Penn Vector core), AAV10-Syn-ChR2-mCherry and AAV10-syn-hM3Di-mCherry (provided by Dr. Micheal Lazarus). In aseptic conditions and under isofluorane anesthesia (IsoFlo Abbot, Ill) animals received for electrophysiological experiments unilateral injections of a virus containing ChR-2 $(0.3 \mu \mathrm{l})$ and for behavioral experiments bilateral injections of a virus containing hM3di $(0.2 \mu \mathrm{l})$. Striatal stereotaxic coordinates were AP $0.98 \mathrm{~mm}, \mathrm{LM}-1.89 \mathrm{~mm}, \mathrm{DV}-3.45 \mathrm{~mm}$ for unilateral 
injections or AP $1.2 \mathrm{~mm}$, LM 2.28, DV 3.35 for bilateral injections (Franklin and Paxinos 2008).

\section{Slice preparation}

Sagittal slices $(250 \mu \mathrm{m})$ were obtained from AAV-injected animals 2 weeks post-surgery to allow virus expression. Mice were anesthetized via isofluorane inhalation and perfused transcardially using cold saline containing (in $\mathrm{mM}$ ): 124 choline chloride, $2.5 \mathrm{KCL}, 2 \mathrm{MgCl}_{2}, 20$ HEPES, $1.2 \mathrm{NaH}_{2} \mathrm{PO}_{4} \cdot \mathrm{H}_{2} \mathrm{O}, 1 \mathrm{CaCl}_{2}, 1$ ascorbic acid, and 3 pyruvate and 10 glucose saturated with $95 \% \mathrm{O}_{2}$ and $5 \% \mathrm{CO}_{2}$, $\mathrm{pH} 7.4,298 \mathrm{mOsm} / \mathrm{l}$. Slices were cut and transferred to regular artificial cerebral spinal fluid containing the following in mM: $136 \mathrm{NaCl}, 3.5 \mathrm{KCl}, 1 \mathrm{MgCl}_{2}, 2.5 \mathrm{CaCl}_{2}, 26$ $\mathrm{NaHCO}_{3}$ and 11 glucose saturated with $95 \% \mathrm{O}_{2}$ and $5 \%$ $\mathrm{CO}_{2}$, where they remained for at least $1 \mathrm{~h}$ before recording at room temperature $\left(21-25^{\circ} \mathrm{C}\right)$.

\section{Electrophysiological recordings}

We performed whole-cell patch-clamp recordings with borosilicate glass micropipettes (Harvard Apparatus 30-0057) heat polished to obtain direct current resistances of 4-6 M . Micropipettes were filled with an internal solution containing in mM: $115 \mathrm{KH}_{2} \mathrm{PO}_{4}, 2 \mathrm{MgCl}_{2}, 10$ HEPES, 0.5 EGTA, $0.2 \mathrm{Na}_{2} \mathrm{ATP}$, and $0.2 \mathrm{Na}_{3} \mathrm{GTP}$. The recordings were made with a microelectrode amplifier with bridge and voltage clamp modes of operation (BVC-700A, Dagan Co, Minneapolis, MN, USA). In some cases, conventional characterization of neurons was made in voltage and current clamp configurations. Access resistances were continuously monitored to be less than $20 \mathrm{M} \Omega$, experiments with changes over $20 \%$ were interrupted and terminated. Software designed in LabVIEW environment (National Instruments) was used for data acquisition and we performed analysis with Origin (version 8.6, Microcal, Northampton, MA, USA).

\section{Stimulation}

Synaptic events were evoked by photostimulation using an optic fiber and LED driver and fiber-coupled LED light source (DC2100, OGKR2 Thorlabs, Newton, NJ, USA) Stimulation frequency was controlled with a computer interface to quickly adjust stimulus parameters during the experiment. Traces shown are the average of near $5 \mathrm{~min}$ recordings (25-30 traces) for a given condition.

In some experiments, pressure injection of glutamate (puff) ( $1 \mathrm{mM} / 20 \mathrm{psi} / 50 \mathrm{~ms}$ ) was delivered via a Picopump (PV820 World Precision Instruments, Sarasota, FL, USA) through a pipette located close to a selected area. In every occasion, we controlled the extent of the glutamate puff by mixing Alexa
598 in the glutamate stock solution to adjust the diffusion to approximately $50 \mu \mathrm{m}$ diameter fluorescent drop.

Single-pellet reach-to-grasp task

Litters of mice bred at OIST animal facility were kept in a room with controlled environment (temperature: $21 \pm 1{ }^{\circ} \mathrm{C}$; humidity $55 \%$; light schedule $12 / 12 \mathrm{~h}$ with lights off at 7 p.m.) and were weaned at postnatal day 21 . Weaned pups were housed in same-sex groups of 2-4. Standard rodent pellets and water were provided ad libitum except during test period (W5-postnatal day 26) when food restriction was introduced. We used a training box of the same dimensions and followed procedures as established by Marques and Olsson (2010). Briefly, food restriction schedule provided enough food to maintain approximately $85 \%$ of body weight. We used as reward $20 \mathrm{mg}$ dustless precision pellets with chocolate flavor (Bio-Serv, USA), during training and testing mice received 20 pellets in a 10-min daily session. Three days prior to test period, mice were habituated to reward pellets scattered on the bottom of the cage once daily ( $0.2 \mathrm{~g} / \mathrm{animal} / \mathrm{day})$. Daily after training and testing, cage food was allowed. For training, mice were divided in two groups: sham (AAV1-ChR2mCherry-injected animals) and hM3di group (AAV10hM3di-mCherry-injected mice). Mice were observed from the front of the cage. Shaping of grasping response (from pellet retrieval with the tongue to use of a preferred paw) was performed on 10-min sessions for 2 days. The preferred paw was determined on the first 10 attempts to reach. If a mouse used both paws, the preferred paw was considered the one used more frequently (out of 10 reaches). Grasp response was made easier by gradually moving the pellet towards the indentation contralateral to the preferred paw (Miklyaeva et al. 1994). Two pre-training days were followed by five consecutive days of training, with daily sessions lasting until 20 pellets were successfully retrieved and eaten or a maximum of $10 \mathrm{~min}$ had elapsed. Starting on training day two, $2 \mathrm{~h}$ before training, mice were injected $200 \mu \mathrm{l}$ of isotonic saline solution (i. p.) replaced on days 5, 6 and 7 by the inert hM3di-agonist clozapine- $n$-oxide (CNO, $3 \mathrm{mg} / \mathrm{kg}$ i.p.) (Armbruster et al. 2007; Lee et al. 2014). We recorded all sessions with a conventional camcorder for further analysis. Performance was analyzed according to the quantitative measures established by Marques and Olsson (2010): Latency to the first reaching attempt (the single first time the mouse performed a reaching movement), reaching accuracy $=$ (number of pellets retrieved/number of reaches) $\times 100$, latency to retrieve one pellet (the latency of the first successful grasp on each testing day) and time of performance $=$ latency to retrieve 5 pellets - latency to retrieve 1 pellet. 
Drugs

CNQX (6-cyano-7-nitroquinoxaline-2,3-dione), gabazine (SR95531), lidocaine $N$-ethyl bromide (QX-314), glutamic acid (Sigma-Aldrich, San Luis, MO, USA) were prepared freshly in stock solutions and added to perfusion during experiments at the required concentration. Clozapine- $n$ oxide (CNO or 8-chloro-11-(4-methyl-1-piperazinyl)-5Hdibenzo[b,e](1,4)diazepine N-oxide (Sigma-Aldrich, San Luis, MO, USA) was also prepared fresh for systemic administration.

\section{Histology}

Mice were intracardially perfused briefly with phosphate buffer $0.01 \mathrm{M}(\mathrm{pH}$ 7.4) followed by phosphate buffer containing $4 \%$ paraformaldehyde and $14 \%$ picric acid. Brains were postfixed for at least $2 \mathrm{~h}$ and then cryoprotected in a 50/50 mixture of fixative and $20 \%$ sucrose in $0.01 \mathrm{M}$ phosphate buffered saline (PBS). Sections were cut at $60 \mu \mathrm{m}$ on a sledge microtome with a freezing stage (Yamato electrofreeze, MC-802A), washed in PBS and incubated in $20 \%$ normal goat serum for $1 \mathrm{~h}$. Primary antibodies to MOR1 (guinea pig polyclonal 1:1,000, Millipore, Darmstadt, Germany) were incubated overnight at $4{ }^{\circ} \mathrm{C}$ and stained with goat secondary antibodies. At least $2 \mathrm{~h}$ were allowed for binding before rinsing in PBS. Sections were mounted on slides; Vectamount AQ (Vector) was used to fix the coverslips. To inspect stained tissue a spinning disc confocal microscope (Olympus BXDSU) and confocal microscope (Carl Zeiss LSM780) were used and pictures were taken using Neurolucida software or ZEN software and a Hamamatsu (EM-CCD C91) camera.

\section{Results}

Fortuitous discovery

We injected striatum of wild-type or BAC D1 and D2 mice with AAVrh10 to express ChR2-mCherry under Syn promoter. With this manipulation areas of null ChR2-mCherry expression were embedded in large areas effectively infected resembling the matrix-striosome compartment organization $(n=21)$. Confirmation of the presence of such striosome-matrix arrangement in the head of striatum was obtained by immunohistochemistry. Non-infected ChR2mCherry regions contained the signature staining of striosomes Mor1-positive and calbindin-negative neurons (Gerfen et al. 1985; Pert et al. 1976). Strikingly, independent of

\section{A}
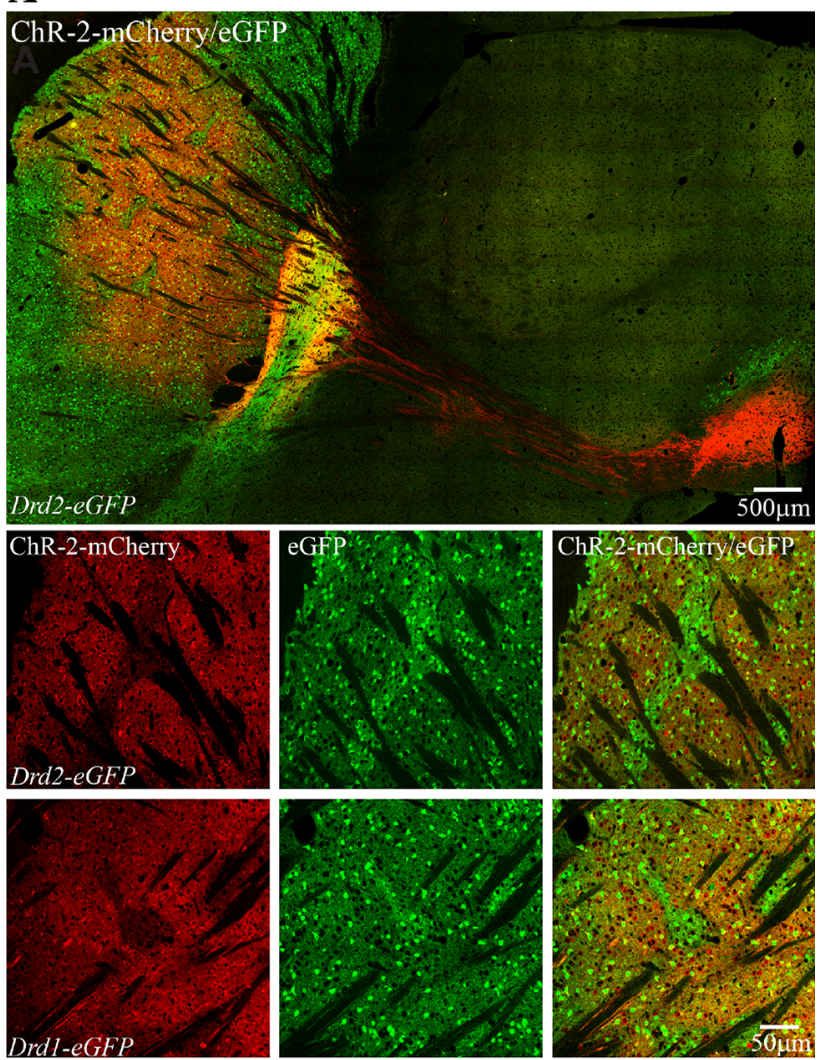

B
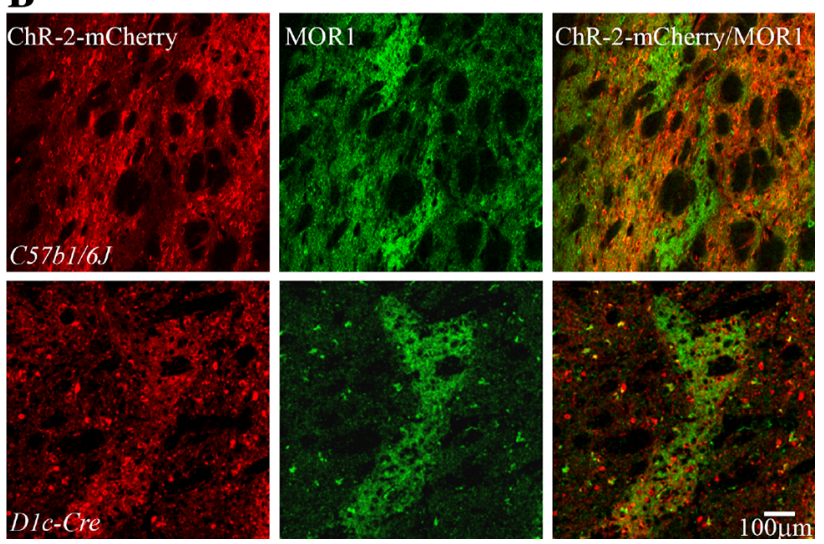

Fig. 1 Typical striatal expression pattern of GFP and ChR2-mCherry in AAV10-injected Drd2-eGFP and Drd1-eGFP mice. a Top panoramic sagittal view of double immunofluorescence staining GFP (green) and ChR2-mCherry (red) in AAV10-injected (Drd2$e G F P$ ) mouse brain. a Bottom representative pictures of double immunofluorescence staining to illustrate the distribution of ChR2mCherry (red), GFP (green) and merged images for mice expressing Drd2-eGFP or Drd1-eGFP. b Top coronal sections of mouse striatum show the expression of MOR1 (green) and ChR2-mCherry (red) and their superimposition. The mCherry expression avoids the striosome in C57B16 mice. b Bottom immunofluorescence distribution of MOR1 (green) and ChR2-mCherry (red) carried by an injection of AAV1 in a D1-Cre mouse. The mCherry expression is present in both compartments 
mouse strain or viral fusion proteins, the adenovirus serotype rh10 selectively targeted striatal neurons of the matrix compartment (Fig. 1). Striatal interneurons also expressed the AAVrh10 viral vector and probably account for the small $7 \%$ of infected neurons sometimes observed in striosome compartment. Some optical slices, however, were difficult to discern with absolute certitude (Fig. 2).

Is synaptic information transferred between striosome and matrix compartments?

Visualization of mCherry allowed identification of striatal compartments: matrix compartment as mCherry $(+)$ and striosome compartment as mCherry (-). Accordingly, neurons from either compartment were selected for patch- clamp recording in current and voltage clamp modalities and later their compartment membership confirmed by post hoc immunostaining of Alexa-488 filled neurons $(n=8)$.

In the matrix compartment, $97 \%$ percent of recorded cells expressed ChR2-mCherry $(n=34)$. As illustrated in Fig. 3 (top) their illumination produced consistent action potential firing at frequencies less than $40 \mathrm{~Hz}$ (Boyden et al. 2005; Zhang et al. 2006) and a glutamate puff (1 mM) excitation of nearby striosome neurons did not influence matrix cells. The striosome compartment (Fig. 3 bottom) was characterized by lack of ChR2-mCherry expression ( $n=11)$. Photostimulation, therefore, did not depolarize neurons in this compartment although action potentials were elicited by delivery of a localized glutamate puff close to the recorded cell. Glutamate-evoked current had a
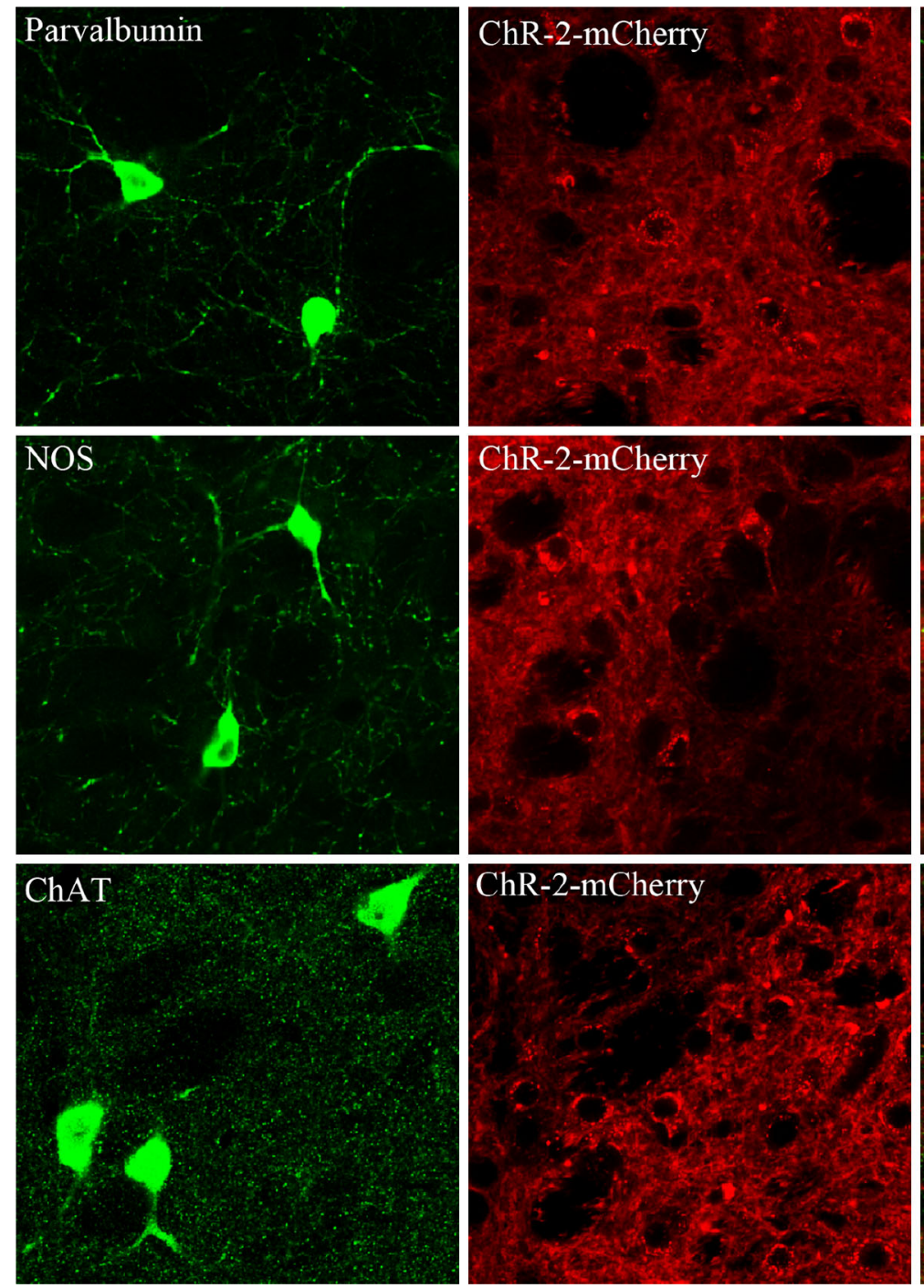
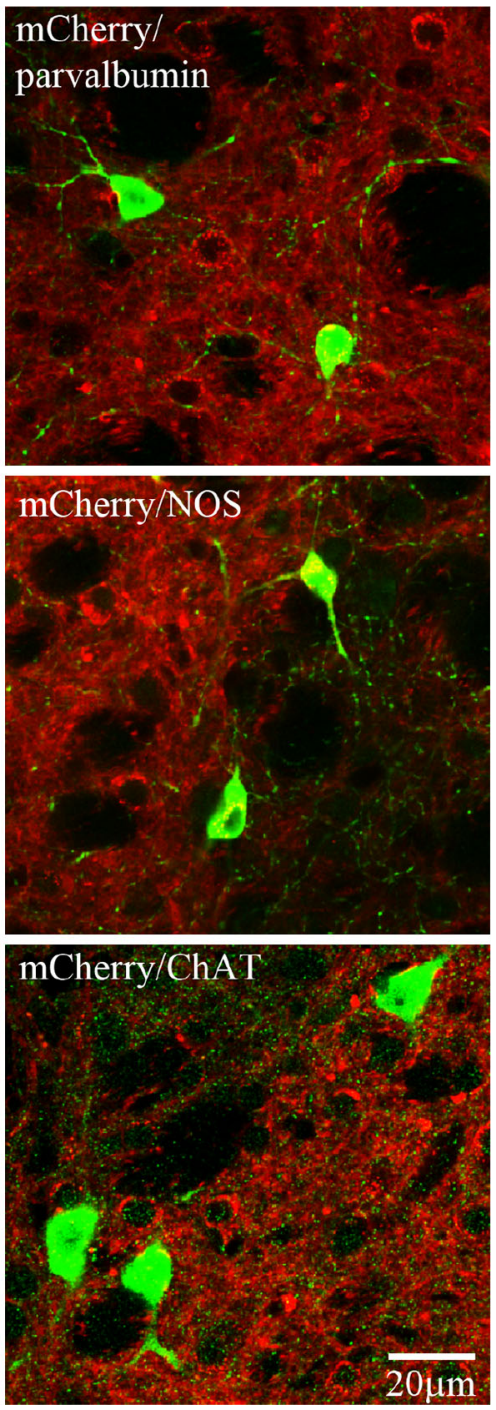

Fig. 2 Striatal interneurons express ChR2-mCherry in AAV10injected mice. Besides matrix neurons AAVrh10 virus also infected interneurons that express nitric oxide synthase $(N O S)$, parvalbumin or choline acetyl transferase $(C h A T)$. Viral presence is indicated by mCherry (red) in interneurons (green). In image superimpositions, the presence of virus is clearly seen in the cell bodies of interneurons. Due to the large size of cholinergic neurons, expression of mCherry only seen in the surrounding membrane-although present-is more difficult to ascertain 
Fig. 3 Targeted

electrophysiological recordings from matrix and striosome compartments. a Striatal spiny neuron (SPN) filled during recording (Alexa-488/Biocytin, green) located in the matrix compartment (ChR2-mCherry, red). 1 Merged image of Alexa488 (green) and ChR2-mCherry (red), 2 zoom of 1, 3 Alexa-488 only, 4 ChR2-mCherry only. b Schematic representation of stimulation and recording protocol. c Representative firing patterns of SPN in the matrix compartment. Voltage responses to hyperpolarizing and depolarizing current injections of neuron shown in a. d Action potentials evoked by photostimulation of $\mathrm{ChR} 2$. e SPN filled during recording (Alexa-488/Biocytin, green) located in the striosome compartment (ChR2-mCherry, red). 1 Merged image of Alexa488 (green) and ChR2-mCherry (red), 2 Zoom, 3 Alexa-488, 4

ChR2-mCherry. f Schematic representation of stimulation and recording protocol. g Representative firing patterns of SPN in the striosome compartment. Voltage responses to hyperpolarizing and depolarizing current injections of neuron shown in e. h Action potentials evoked by delivery of a glutamate puff (1 $\mathrm{mM})$

\section{A Matrix compartment}
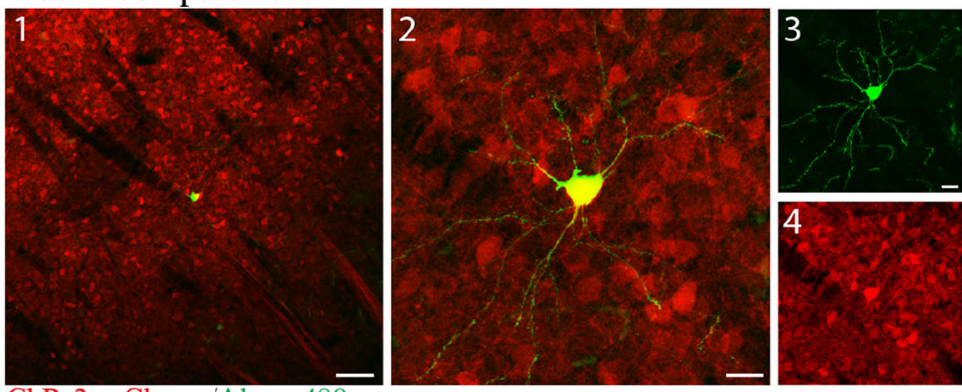

B

C

D Photostimulation (Matrix activation)
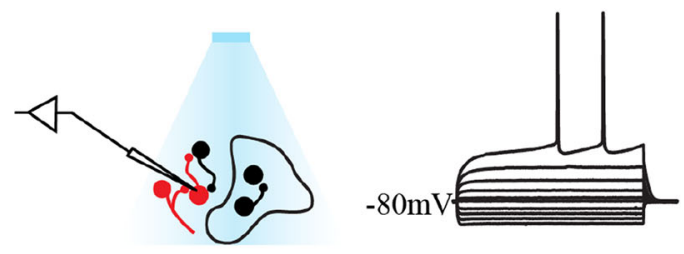
| | | | | | | | |

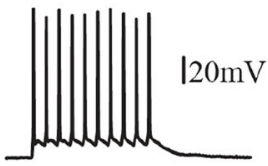

Glutamate puff (Striosome activation) $1200 \mathrm{pA}$ $-70 \mathrm{mV}$

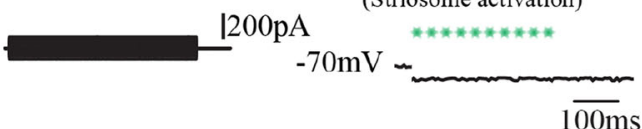

E Striosome compartment

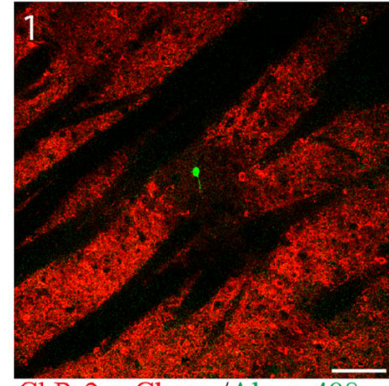

ChR-2-mCherry/Alexa-488

F

G

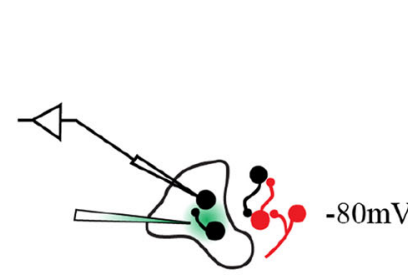

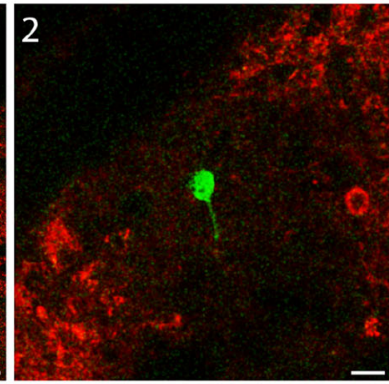

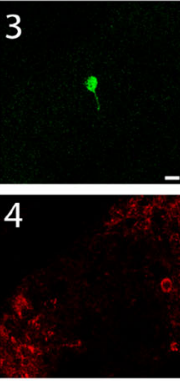

H Photostimulation (Matrix activation)

|||||| |||

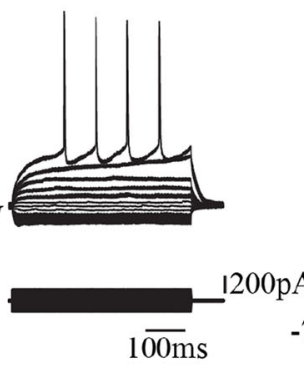

Glutamate puff (Striosome activation)

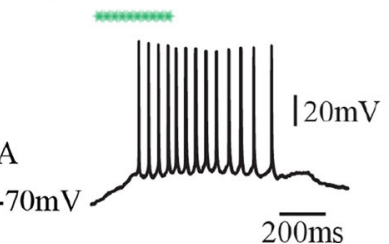

reversal potential around $10 \mathrm{mV}$ (Keller et al. 1991) ( $n=4$, Online Resource 1).

Is there synaptic connectivity between striosome and matrix compartments?

Combined recordings of neurons located either in matrix or striosome compartments with a-global activation of striatal matrix neurons expressing channel rhodopsin and b-circumscribed neuronal activation by delivery of glutamate, indicated that compartments do not share synaptic connectivity. As illustrated in Fig. 4, neurons in the matrix compartment recorded in voltage clamp mode and briefly photostimulated (2-5 ms pulse) responded with inhibitory postsynaptic currents (IPSCs) with an average amplitude of $542.7 \pm 292.1 \mathrm{pA}, n=11$. 
Fig. 4 Matrix and striosome compartments do not share synaptic connectivity. a Evoked IPSC in a neuron of the matrix compartment induced by photostimulation (holding potential $20 \mathrm{mV}$ ). Trace below in the presence of $\mathrm{GABA}_{\mathrm{A}}$ antagonist gabazine $(20 \mu \mathrm{M})$. Blue bars indicate time of stimulation. b Voltage trace of a recorded neuron located in the striosome compartment during photoactivation of neighboring matrix area. c Voltage trace of a recorded neuron from matrix compartment during activation by glutamate puff of neighboring striosome. d Evoked IPSC in a striosomal neuron by activation of surrounding striosome with a glutamate puff. Trace below in presence of gabazine $(20 \mu \mathrm{M})$
A

Matrix compartment

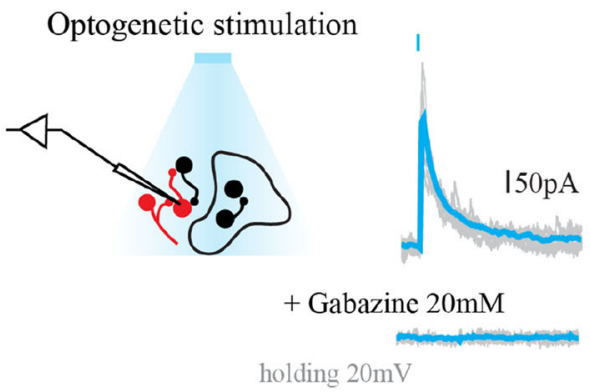

C

Glutamate puff
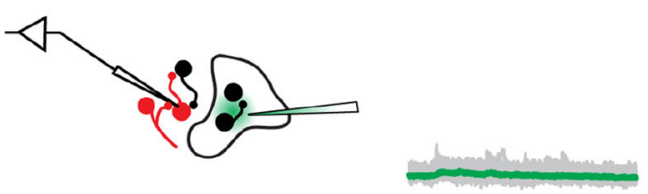

holding $10 \mathrm{mV}$
B Striosome compartment

I

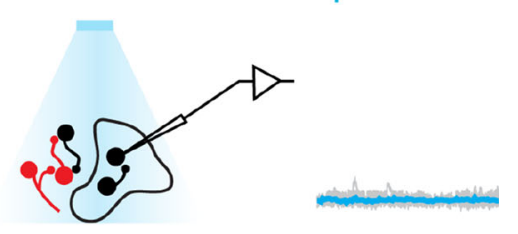

D

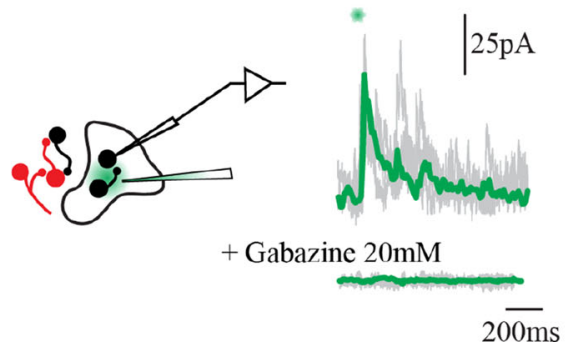

To avoid contamination, all IPSCs were recorded at $20 \mathrm{mV}$ (photocurrent reversal potential, Online Resource 2). Complete blockade of IPSCs with the $\mathrm{GABA}_{\mathrm{A}}$ antagonist gabazine $(20 \mu \mathrm{M})$ confirmed the GABAergic origin of recorded currents. No responses from matrix neurons were observed if a glutamate puff was delivered to the striosome compartment $(n=4)$. Neurons in striosomal compartment recorded in voltage clamp mode and briefly photostimulated (2-5 ms pulse) did not evoke IPSCs at any holding potential even when located near compartment boundaries $(n=7)$, however, a brief puff of glutamate inside striosome compartment reliably evoked IPSCs with an average amplitude of $70.6 \pm 24.3 \mathrm{pA}, n=6$ followed by asynchronous IPSCs afterwards. Blockade of IPSCs with gabazine $(20 \mu \mathrm{M})$ again confirmed the GABAergic origin of IPSCs.

Selective inhibition of matrix compartment impairs skilled motor behavior

We trained mice in a single-pellet reach-to-grasp task to evaluate skilled motor performance during selective inhibition of the dorsolateral striatal matrix compartment. We used targeted expression of designer receptors exclusively activated by a designer drug (DREADD) hM3di carried by AAV serotype 10 in dorsolateral striatum. Of 28 mice, only $15(53.6 \%)$ learned the task and expressed virus successfully, of those 7 mice were AAV1-ChR2-mCherry-injected mice (sham group) and 8 were AAV10-Syn-hM3diinjected mice (hM3di group). The right forepaw was preferred by $60 \%$ of the animals. As described in methods mice were expected to reach and grasp 20 pellets in a 10-min daily session. Figure 5 shows performance rates of sham and hM3di groups as reaching accuracy, latency to retrieve first pellet and latency to retrieve 5 pellets-latency to retrieve first pellet (Marques and Olsson 2010). The learning curve of both groups was similar, mice increased reaching accuracy through sessions up to $57 \pm 6 \%$ and decreased task time to $96 \pm 7$ s. In sessions where DREADD agonist clozapine- $n$-oxide (CNO, $3 \mathrm{mg} /$ $\mathrm{kg}$, i. p.) was administered to animals of both groups, a significant difference in reaching accuracy between groups was observed. Inhibition of matrix neurons by $\mathrm{CNO}$ administration resulted in low reaching accuracy (46 $\pm 5 \%$ for hM3di and $69 \pm 7 \%$ for sham group). All mice showed similar motivation to perform the task taking equal amount of time during training sessions as shown by the time required to collect 5 pellets minus the latency of the first successful grasp of the day.

\section{Discussion}

Our experiments demonstrate that AAV serotype rh10 expresses in striatal neurons located in matrix compartment sparing $93 \%$ of neurons in striosomes. With functional viral expression of AAVrh10, we specifically targeted the matrix compartment to express ChR2-mCherry fusion proteins. This procedure allowed directed patch-clamp recordings of neurons belonging to both areas and selective 
A
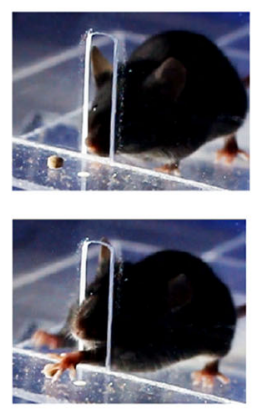
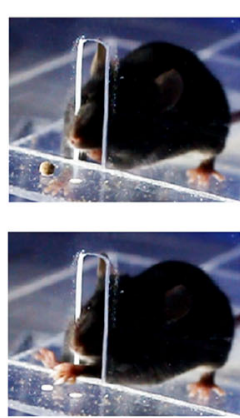
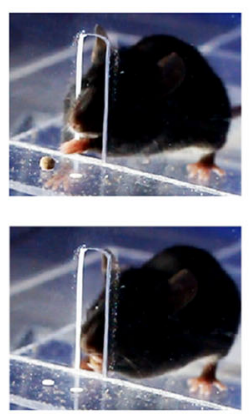

Control
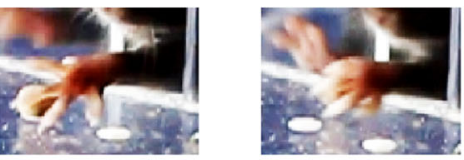

$\mathrm{CNO}$

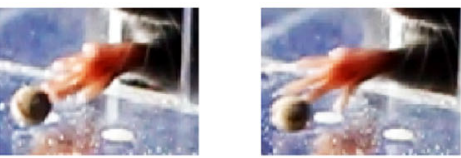

B Reach-to-grasp task performance

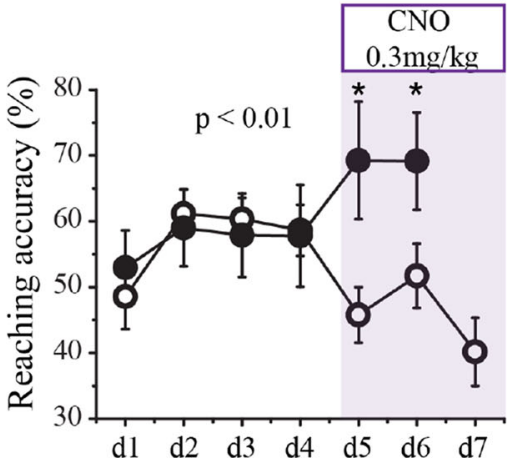

Fig. 5 Performance of a single-pellet reach-to-grasp task following neuronal inhibition of the matrix compartment. a Photographs of a mouse performing a successful reach-to-grasp trial. b. Quantitative evaluation of mice performance for sham and hM3di group in terms

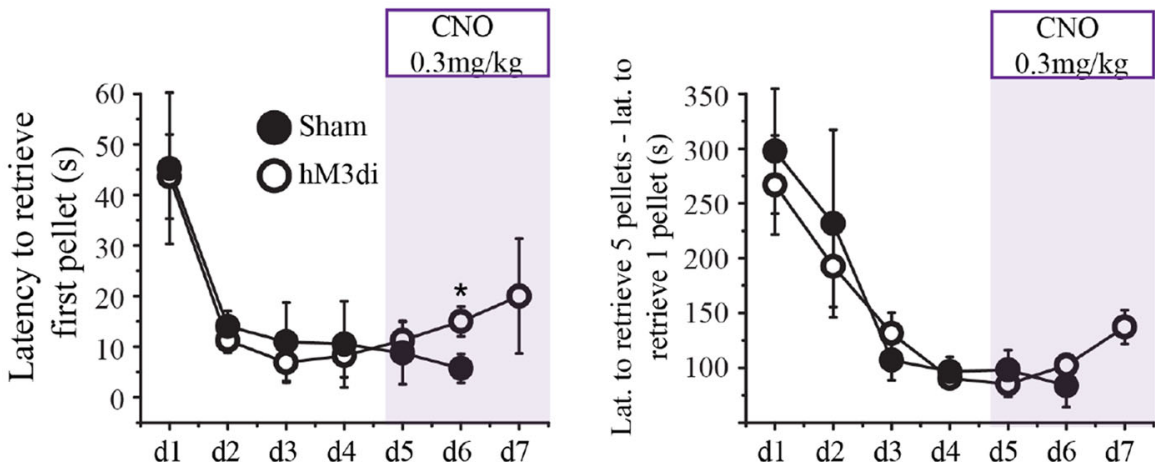

photoactivation of matrix compartment. We observed absence of physiological synaptic connections to neurons in striosomes from neurons in matrix (Figs. 3, 4). In addition, we performed selective matrix inhibition on a skilled motor task by expression DREADD hM3di, which led to decreased performance. Taken together our results using a new tool to selectively manipulate the matrix compartment demonstrate lack of functional connectivity between striosome and matrix and confirm the participation of matrix and dorsolateral striatum in acquired motor skills.

\section{Adeno-associated virus vectors}

Adeno-associated viruses are single-stranded DNA-containing viruses of 57 serotypes classified in 7 species (Chen and Lee 2014). Six types of adenoviruses (AAV1-6) have been isolated from primates (AAV1), non-human primates (AAV2-3) and humans with an $80 \%$ homology (Xiao et al. 1999). Although isolation of an AAV2 clone facilitated development of stable vectors, the level of gene expression was low. Since proteins that determine cell entry present in capsid-protein shell or viral envelope-are directly related to gene expression (Cearley et al. 2008), successful attempts to engineer serotypes using AAV2 while of reaching accuracy (successful trials/total trials $\times 100$ ), latency for first pellet retrieval and latency to retrieve 5 pellets-latency to retrieve first pellet

modifying cell entry pathways (Ellis et al. 2013; Rabinowitz et al. 2004; Choi et al. 2005) have resulted in more than 100 different AAV capsids cloned from primates and many others engineered (Surace and Auricchio 2008). Primary cell entry receptors are CD46, coxsackie virus and adenovirus receptor (CAR) and sialic acid. We used AAV1 (Vector systems, Phyl., PA, USA) and AAVrh10 (Inutsuka et al. 2014; Lazarus et al. 2011) and found that striatal neurons in matrix and striosome compartments get infected with AAV1, but AAVrh10 infects only neurons of matrix. Since changing promoter from synapsin to EF1 $\alpha$ did not affect viral expression, it is possible that the entry receptor is responsible for differences we observed. The primary receptor for AAV1 is sialic acid (Ellis et al. 2013), but receptor of reengineered rhesus monkeys capsid of AAVrh10 is not known (Giove et al. 2010; Arnberg 2012). Since AAV1 and AAVrh10 used the same promoter and AAV2 backbone, it is possible that neuronal entry receptor density in striosome could be very low or other factors involving intracellular traffic to the nucleus, decapsidation or conversion of single-stranded DNA genome to doublestranded DNA could be participating (Ding et al. 2005).

It is interesting to point out that neurons belonging to striosome compartment, but not matrix, express limbic- 
associated membrane protein (LAMP) now called limbic system-associated membrane protein (LSAMP) (Cote et al. 1995; Chesselet et al. 1991). LSAMP is a cell surface glycoprotein important for neuronal adhesion and regional identity during development and in striosome formation. Importantly, LSAMP belongs to the immunoglobulin (Ig) protein superfamily with three Ig domains and a glycosylphosphatidylinositol anchor (Pimenta and Levitt 2004). Could it be that presence of this protein prevents entrance of AAVrh10 into striosome neurons?

The preference for AAVrh10 use in mice striata (Cearley and Wolfe 2006; Swain et al. 2014; Klein et al. 2008) should be of concern considering expression of virus located in the matrix.

Is there a functional regulation between striosome and matrix compartments?

Anatomical evidence has shown that matrix and striosome neurons confine their axonal and dendritic processes to their own compartments (Penny et al. 1988; Kawaguchi et al. 1989; Graybiel et al. 1986; Bolam et al. 1988). Although interneurons sometimes appear to send a few dendrites across boundaries (Cowan et al. 1990; Penny et al. 1988; Chesselet and Graybiel 1986; Walker and Graybiel 1993; Walker et al. 1993; Kawaguchi 1992) and the notion of interneuron information sharing is appealing (Crittenden and Graybiel 2011), the question remains, however, as to the function of those neuronal processes. More behavioral and pharmacological studies are also needed since, so far, evidence of shared functions is not available. For instance, after comparison between compartments, striosomes display lower dopamine uptake sites (Graybiel and Moratalla 1989) and higher induction of early genes following systemic administration of cocaine, amphetamine and apomorphine (Canales and Graybiel 2000). Moreover, greater deterioration of motor performance, higher expression of fear and susceptibility to reinforcement follow impairment of mGlu1/5 signaling (Tappe and Kuner 2006). Increases in movement-related neuronal activity in matrix compartment have been observed in freely moving rats (Heidenreich et al. 1994; Brown et al. 2002; Trytek et al. 1996) consistent with the presence of both striatal direct and indirect pathways in the matrix compartment (Gerfen 1984; Gerfen et al. 1985; Graybiel et al. 1979; Jimenez-Castellanos and Graybiel 1989; Kawaguchi et al. 1990).

Our electrophysiological evidence confirms that matrix and striosome compartments do not share direct synaptic connections. AAV expression under synapsin promoter drove neuron-specific gene transfer in all neuronal types of matrix compartment (Figs. 1, 3). Through neuronal expression of fluorophore mCherry, we identified striosome and matrix compartments and avoided low probability of pair recordings (Tunstall et al. 2002) by delivering a localized glutamate puff restrained to a small area. No physiological evidence of inhibitory synaptic connectivity between compartments was observed, although we observed synaptic responses among neurons belonging to each compartment alone (Fig. 4).

In neurons expressing ChR2-mCherry, we recorded IPSCs at photocurrent reversal potential $(20 \mathrm{mV})$. Simultaneous recording and photoactivation of the matrix compartment evoked robust inhibitory responses with amplitudes and success rate that suggests widespread neuronal recruitment (Chuhma et al. 2011; Tepper et al. 2008) (Fig. 4). Photoactivation of matrix while recording striosome neurons produced no physiological response. To verify neuronal viability, we also delivered a glutamate puff, depolarized the surrounding striosomal compartment and observed inhibitory synaptic responses. These striosome responses were of smaller amplitude than those evoked by photostimulation of the matrix, most likely due to a smaller number of stimulated neurons in the $50 \mu \mathrm{m}$ area of glutamate diffusion (see "Materials and Methods"). To further seek compartmental connectivity, we recorded matrix neurons while stimulating adjacent striosomes by glutamate pressure ejection. Once more, we could not evoke any inhibitory response. The possibility of very long processes mediating striosome to matrix compartment connections cannot be ruled out with such circumscribed depolarizing effects. Thus, we cannot say with certainty that matrix and striosomes do not interact, but how communication happens remains a question.

The matrix compartment is involved in expression of a learned reach-to-grasp skill

Striatal participation in movement and acquisition of motor skills has been importantly related to dopamine function. There is a direct correlation between the extent of striatal dopamine loss and gross impairment of motor function. Loss of skilled behavior is observed in the contralateral forepaw following unilateral dopamine depletion (Hamilton et al. 1985; Miklyaeva et al. 1994; Uguru-Okorie and Arbuthnott 1981; Vergara-Aragon et al. 2003; Whishaw et al. 1986).

Several attempts at dividing striatum in sensorimotor, associative and limbic areas have been proposed (Graybiel 2008). Conveniently, also afferents to striosome and matrix separate compartments in limbic and sensorimotor systems, respectively. Striosomes have been associated with limbicrelated goal-directed behaviors difficult to interpret such as motivation, pleasure and fear (DiFeliceantonio et al. 2012; Tappe and Kuner 2006; White and Hiroi 1998) also closely related to dopamine function. Since the largest of 
compartments, the matrix, contains main outputs to both globus pallidus and substantia nigra, it is expected to participate in behaviors associated with striatal and corticostriatal function such skill procedural learning and habit formation. Consistently, in freely moving animals increased neuronal activity associated to movement is located in the matrix (Heidenreich et al. 1994; Brown et al. 2002; Trytek et al. 1996).

In our behavioral experiments, we aimed at the matrix compartment located in dorsolateral striatum associated with skill procedural learning (Balleine and O'Doherty 2010; Yin et al. 2006) and forepaw use (MacLellan et al. 2006; Aldridge et al. 2004; Pisa and Schranz 1988).

Specific expression of AAVrh10 in neurons belonging to matrix compartment allowed us to perform some preliminary behavioral experiments. We expressed DREADDhM3di receptors that can be easily activated by CNO to cause long-lasting neuronal inhibition. With matrix neurons inactivated in dorsolateral striatum, mice lost the already proficient skill to reach and grasp a single chocolate pellet (Fig. 5). Motivation to perform was not altered since animals kept trying and eventually managed to collect 5 pellets in the same time as controls.

What could be the function of an independent striatal striosome system?

In spite of how clear and important our results are, we are faced with more questions than answers: Does the striosome compartment represent a third striatal output pathway? Do striosomes modulate: motivational aspects and reinforcement? Aversive-related dopamine release? Humoral signals?

The feedback loop established between striosomes and substantia nigra compacta has already prompted the idea of a third output pathway originating in striosomes relevant in levodopa-induced dyskinesias (Graybiel et al. 2000). Striosome neurons could regulate dopamine release to maintain required longer lasting extracellular levels of striatal dopamine. Moreover, dopamine spillover and dopamine receptors located extrasynaptically (Cragg and Rice 2004; Yung et al. 1995) could influence the effect of dopamine on striatal population activity through volume transmission. Extracellular dopamine levels induced by regular dopamine firing could buildup slowly and modulate readout of incoming signals and reset neuronal excitability (Agnati et al. 2000). A dopaminergic tone on a long time scale has been associated with behavioral states such as hunger, satiation, uncertainty, punishment, aggression, fatigue and sleepiness (Schultz 2007a, b).

Although striosome output is directed to substantia nigra pars compacta some axons leave collaterals in globus pallidus, entopeduncular nucleus and to substantia nigra pars reticulata (Fujiyama et al. 2011). These outputs could provide an efferent copy of an ongoing selection from action programs already proven successful (or rewarded) in the animal's repertoire (Fee 2012, 2014; Mink 1996; Redgrave et al. 1999).

Neuromodulators other than dopamine could also influence volume transmission in striosomes. The greater vascularity of this compartment compared to matrix (Breuer et al. 2005) might allow blood-borne humoral factors to enter striosome compartment and perhaps together with dopamine modulate reward signals and behavior. For instance, leptin, the fat-derived hormone that can override satiety signals and promote overeating, has been found to modulate basal ganglia activity (Farooqi et al. 2007). Striosomes could play a pivotal role in aspects central to learning theory by linking behavior with a future predictive value. Striosomes can directly influence dopamine release in response to limbic and also possibly bloodborne neuroendocrine inputs associated for instance to relief of pain, anxiety, thirst and hunger or even pair bonding.

\section{Conclusion}

Differential in vitro stimulation and recording of neurons belonging to either striatal striosome or matrix compartments was possible, thanks to expression of AAVrh10 in matrix neurons. Neuronal synthesis of channel rhodopsin 2 (ChR2) and targeted expression of designer receptors exclusively activated by a designer drug (DREADD) hM3di carried by AAVrh10 allowed us to report that striatal and matrix compartments to not talk to each other via direct monosynaptic connections and that inactivation of the dorsolateral striatal matrix impairs performance of a reach and grasp skill. Alternative ways of communication between striatal compartments such as longer axonal pathways, and volume transmission are possible.

Acknowledgments The government of Japan supported this work.

Open Access This article is distributed under the terms of the Creative Commons Attribution License which permits any use, distribution, and reproduction in any medium, provided the original author(s) and the source are credited.

\section{References}

Agnati LF, Zoli M, Ferrari R, Di Paola L, Torri C, Fuxe K, Zini I (2000) Evidence for the existence of pulses of dopamine in the extracellular space of the rat striatum. Prog Brain Res 125:303-308

Aldridge JW, Berridge KC, Rosen AR (2004) Basal ganglia neural mechanisms of natural movement sequences. Can J Physiol Pharmacol 82(8-9):732-739. doi:10.1139/y04-061 
Ambrose LM, Unterwald EM, Van Bockstaele EJ (2004) Ultrastructural evidence for co-localization of dopamine D2 and microopioid receptors in the rat dorsolateral striatum. Anat Rec 279(1):583-591. doi:10.1002/ar.a.20054

Armbruster BN, Li X, Pausch MH, Herlitze S, Roth BL (2007) Evolving the lock to fit the key to create a family of G proteincoupled receptors potently activated by an inert ligand. Proc Natl Acad Sci USA 104(12):5163-5168. doi:10.1073/pnas.070029 3104

Arnberg N (2012) Adenovirus receptors: implications for targeting of viral vectors. Trends Pharmacol Sci 33(8):442-448. doi:10.1016/ j.tips.2012.04.005

Balleine BW, O'Doherty JP (2010) Human and rodent homologies in action control: corticostriatal determinants of goal-directed and habitual action. Neuropsychopharmacology 35(1):48-69. doi:10. 1038/npp.2009.131

Bolam JP, Izzo PN, Graybiel AM (1988) Cellular substrate of the histochemically defined striosome/matrix system of the caudate nucleus: a combined Golgi and immunocytochemical study in cat and ferret. Neuroscience 24(3):853-875

Boyden ES, Zhang F, Bamberg E, Nagel G, Deisseroth K (2005) Millisecond-timescale, genetically targeted optical control of neural activity. Nat Neurosci 8(9):1263-1268. doi:10.1038/ nn 1525

Breuer O, Lawhorn C, Miller T, Smith DM, Brown LL (2005) Functional architecture of the mammalian striatum: mouse vascular and striosome organization and their anatomic relationships. Neurosci Lett 385(3):198-203. doi:10.1016/j.neulet.2005. 05.029

Brown LL, Feldman SM, Smith DM, Cavanaugh JR, Ackermann RF, Graybiel AM (2002) Differential metabolic activity in the striosome and matrix compartments of the rat striatum during natural behaviors. J Neurosci 22(1):305-314

Canales JJ, Graybiel AM (2000) A measure of striatal function predicts motor stereotypy. Nat Neurosci 3(4):377-383. doi:10. $1038 / 73949$

Cearley CN, Wolfe JH (2006) Transduction characteristics of adenoassociated virus vectors expressing cap serotypes 7, 8, 9, and Rh10 in the mouse brain. Mol Ther 13(3):528-537. doi:10.1016/ j.ymthe.2005.11.015

Cearley CN, Vandenberghe LH, Parente MK, Carnish ER, Wilson JM, Wolfe JH (2008) Expanded repertoire of AAV vector serotypes mediate unique patterns of transduction in mouse brain. Mol Ther 16(10):1710-1718. doi:10.1038/mt.2008.166

Chen RF, Lee CY (2014) Adenoviruses types, cell receptors and local innate cytokines in adenovirus infection. Int Rev Immunol 33(1):45-53. doi:10.3109/08830185.2013.823420

Chesselet MF, Graybiel AM (1986) Striatal neurons expressing somatostatin-like immunoreactivity: evidence for a peptidergic interneuronal system in the cat. Neuroscience 17(3):547-571

Chesselet MF, Gonzales C, Levitt P (1991) Heterogeneous distribution of the limbic system-associated membrane protein in the caudate nucleus and substantia nigra of the cat. Neuroscience 40(3):725-733

Choi VW, McCarty DM, Samulski RJ (2005) AAV hybrid serotypes: improved vectors for gene delivery. Curr Gene Ther 5(3): 299-310

Chuhma N, Tanaka KF, Hen R, Rayport S (2011) Functional connectome of the striatal medium spiny neuron. J Neurosci 31(4):1183-1192. doi:10.1523/JNEUROSCI.3833-10.2011

Cote PY, Levitt P, Parent A (1995) Distribution of limbic systemassociated membrane protein immunoreactivity in primate basal ganglia. Neuroscience 69(1):71-81

Cowan RL, Wilson CJ, Emson PC, Heizmann CW (1990) Parvalbumin-containing GABAergic interneurons in the rat neostriatum. J Comp Neurol 302(2):197-205
Cragg SJ, Rice ME (2004) DAncing past the DAT at a DA synapse. Trends Neurosci 27(5):270-277. doi:10.1016/j.tins.2004.03.011

Crittenden JR, Graybiel AM (2011) Basal Ganglia disorders associated with imbalances in the striatal striosome and matrix compartments. Front Neuroanat 5:59. doi:10.3389/fnana.2011.00059

Desban M, Kemel ML, Glowinski J, Gauchy C (1993) Spatial organization of patch and matrix compartments in the rat striatum. Neuroscience 57(3):661-671

DiFeliceantonio AG, Mabrouk OS, Kennedy RT, Berridge KC (2012) Enkephalin surges in dorsal neostriatum as a signal to eat. Curr Biol 22(20):1918-1924. doi:10.1016/j.cub.2012.08.014

Ding W, Zhang L, Yan Z, Engelhardt JF (2005) Intracellular trafficking of adeno-associated viral vectors. Gene Ther 12(11):873-880. doi:10.1038/sj.gt.3302527

Donoghue JP, Herkenham M (1986) Neostriatal projections from individual cortical fields conform to histochemically distinct striatal compartments in the rat. Brain Res 365(2):397-403

Eblen F, Graybiel AM (1995) Highly restricted origin of prefrontal cortical inputs to striosomes in the macaque monkey. J Neurosci 15(9):5999-6013

Ellis BL, Hirsch ML, Barker JC, Connelly JP, Steininger RJ 3rd, Porteus MH (2013) A survey of ex vivo/in vitro transduction efficiency of mammalian primary cells and cell lines with Nine natural adeno-associated virus (AAV1-9) and one engineered adeno-associated virus serotype. Virol J 10:74. doi:10.1186/ 1743-422X-10-74

Farooqi IS, Bullmore E, Keogh J, Gillard J, O'Rahilly S, Fletcher PC (2007) Leptin regulates striatal regions and human eating behavior. Science 317(5843):1355. doi:10.1126/science.1144599

Fee MS (2012) Oculomotor learning revisited: a model of reinforcement learning in the basal ganglia incorporating an efference copy of motor actions. Front Neural Circ 6:38. doi:10.3389/fncir. 2012.00038

Fee MS (2014) The role of efference copy in striatal learning. Curr Opin Neurobiol 25:194-200. doi:10.1016/j.conb.2014.01.012

Flaherty AW, Graybiel AM (1991) Corticostriatal transformations in the primate somatosensory system. Projections from physiologically mapped body-part representations. J Neurophysiol 66(4):1249-1263

Flaherty AW, Graybiel AM (1993) Two input systems for body representations in the primate striatal matrix: experimental evidence in the squirrel monkey. J Neurosci 13(3):1120-1137

Franklin KBJ, Paxinos G (2008) The mouse brain in stereotaxic coordinates, 3rd edn. Elsevier, New York

Fujiyama F, Sohn J, Nakano T, Furuta T, Nakamura KC, Matsuda W, Kaneko T (2011) Exclusive and common targets of neostriatofugal projections of rat striosome neurons: a single neurontracing study using a viral vector. Eur J Neurosci 33(4):668-677. doi:10.1111/j.1460-9568.2010.07564.x

Georges F, Stinus L, Bloch B, Le Moine C (1999) Chronic morphine exposure and spontaneous withdrawal are associated with modifications of dopamine receptor and neuropeptide gene expression in the rat striatum. Eur J Neurosci 11(2):481-490

Gerfen CR (1984) The neostriatal mosaic: compartmentalization of corticostriatal input and striatonigral output systems. Nature 311(5985):461-464

Gerfen CR (1989) The neostriatal mosaic: striatal patch-matrix organization is related to cortical lamination. Science 246(4928): 385-388

Gerfen CR, Baimbridge KG, Miller JJ (1985) The neostriatal mosaic: compartmental distribution of calcium-binding protein and parvalbumin in the basal ganglia of the rat and monkey. Proc Natl Acad Sci USA 82(24):8780-8784

Gerfen CR, Baimbridge KG, Thibault J (1987a) The neostriatal mosaic: III. Biochemical and developmental dissociation of patch-matrix mesostriatal systems. J Neurosci 7(12):3935-3944 
Gerfen CR, Herkenham M, Thibault J (1987b) The neostriatal mosaic: II. Patch- and matrix-directed mesostriatal dopaminergic and non-dopaminergic systems. J Neurosci 7(12):3915-3934

Gimenez-Amaya JM, Graybiel AM (1991) Modular organization of projection neurons in the matrix compartment of the primate striatum. J Neurosci 11(3):779-791

Giove TJ, Sena-Esteves M, Eldred WD (2010) Transduction of the inner mouse retina using AAVrh8 and AAVrh10 via intravitreal injection. Exp Eye Res 91(5):652-659. doi:10.1016/j.exer.2010. 08.011

Graybiel AM (2008) Habits, rituals, and the evaluative brain. Annu Rev Neurosci 31:359-387

Graybiel AM, Moratalla R (1989) Dopamine uptake sites in the striatum are distributed differentially in striosome and matrix compartments. Proc Natl Acad Sci USA 86(22):9020-9024

Graybiel AM, Ragsdale CW Jr (1978) Histochemically distinct compartments in the striatum of human, monkeys, and cat demonstrated by acetylthiocholinesterase staining. Proc Natl Acad Sci USA 75(11):5723-5726

Graybiel AM, Ragsdale CW Jr, Moon Edley S (1979) Compartments in the striatum of the cat observed by retrograde cell labeling. Exp Brain Res 34(1):189-195

Graybiel AM, Ragsdale CW Jr, Yoneoka ES, Elde RP (1981) An immunohistochemical study of enkephalins and other neuropeptides in the striatum of the cat with evidence that the opiate peptides are arranged to form mosaic patterns in register with the striosomal compartments visible by acetylcholinesterase staining. Neuroscience 6(3):377-397

Graybiel AM, Baughman RW, Eckenstein F (1986) Cholinergic neuropil of the striatum observes striosomal boundaries. Nature 323(6089):625-627. doi:10.1038/323625a0

Graybiel AM, Canales JJ, Capper-Loup C (2000) Levodopa-induced dyskinesias and dopamine-dependent stereotypies: a new hypothesis. Trends Neurosci 23(10 Suppl):S71-S77

Groves PM, Martone M, Young SJ, Armstrong DM (1988) Threedimensional pattern of enkephalin-like immunoreactivity in the caudate nucleus of the cat. J Neurosci 8(3):892-900

Guttenberg ND, Klop H, Minami M, Satoh M, Voorn P (1996) Colocalization of mu opioid receptor is greater with dynorphin than enkephalin in rat striatum. Neuroreport 7(13):2119-2124

Hamilton MH, Garcia-Munoz M, Arbuthnott GW (1985) Separation of the motor consequences from other actions of unilateral 6-hydroxydopamine lesions in the nigrostriatal neurones of rat brain. Brain Res 348(2):220-228

Heidenreich BA, Trytek ES, Schroeder DM, Sengelaub DR, Rebec GV (1994) A methodology for determining the patch-matrix compartmental location of extracellular single-unit recordings in the striatum of freely moving rats. J Neurosci Methods 52(2):169-174

Herkenham M, Pert CB (1981) Mosaic distribution of opiate receptors, parafascicular projections and acetylcholinesterase in rat striatum. Nature 291(5814):415-418

Inutsuka A, Inui A, Tabuchi S, Tsunematsu T, Lazarus M, Yamanaka A (2014) Concurrent and robust regulation of feeding behaviors and metabolism by orexin neurons. Neuropharmacology 85:451-460. doi:10.1016/j.neuropharm.2014.06.015

Jimenez-Castellanos J, Graybiel AM (1989) Compartmental origins of striatal efferent projections in the cat. Neuroscience 32(2):297-321

Johnston JG, Gerfen CR, Haber SN, van der Kooy D (1990) Mechanisms of striatal pattern formation: conservation of mammalian compartmentalization. Brain Res Dev Brain Res 57(1):93-102

Kawaguchi Y (1992) Large aspiny cells in the matrix of the rat neostriatum in vitro: physiological identification, relation to the compartments and excitatory postsynaptic currents. J Neurophysiol 67(6):1669-1682

Kawaguchi Y, Wilson CJ, Emson PC (1989) Intracellular recording of identified neostriatal patch and matrix spiny cells in a slice preparation preserving cortical inputs. J Neurophysiol 62(5):1052-1068

Kawaguchi Y, Wilson CJ, Emson PC (1990) Projection subtypes of rat neostriatal matrix cells revealed by intracellular injection of biocytin. J Neurosci 10(10):3421-3438

Keller BU, Konnerth A, Yaari Y (1991) Patch clamp analysis of excitatory synaptic currents in granule cells of rat hippocampus. J Physiol 435:275-293

Kincaid AE, Wilson CJ (1996) Corticostriatal innervation of the patch and matrix in the rat neostriatum. J Comp Neurol 374(4): 578-592. doi:10.1002/(SICI)1096-9861(19961028)374:4<578: AID-CNE7>3.0.CO;2-Z

Klein RL, Dayton RD, Tatom JB, Diaczynsky CG, Salvatore MF (2008) Tau expression levels from various adeno-associated virus vector serotypes produce graded neurodegenerative disease states. Eur J Neurosci 27(7):1615-1625. doi:10.1111/j.14609568.2008.06161.x

Lawhorn C, Smith DM, Brown LL (2009) Partial ablation of muopioid receptor rich striosomes produces deficits on a motor-skill learning task. Neuroscience 163(1):109-119. doi:10.1016/j. neuroscience.2009.05.021

Lazarus M, Shen HY, Cherasse Y, Qu WM, Huang ZL, Bass CE, Winsky-Sommerer R, Semba K, Fredholm BB, Boison D, Hayaishi O, Urade Y, Chen JF (2011) Arousal effect of caffeine depends on adenosine A2A receptors in the shell of the nucleus accumbens. J Neurosci 31(27):10067-10075. doi:10.1523/ JNEUROSCI.6730-10.2011

Lee HM, Giguere PM, Roth BL (2014) DREADDs: novel tools for drug discovery and development. Drug Discovery Today 19(4):469-473. doi:10.1016/j.drudis.2013.10.018

Liu FC, Graybiel AM (1992) Heterogeneous development of calbindin-D28K expression in the striatal matrix. J Comp Neurol 320(3):304-322. doi:10.1002/cne.903200304

MacLellan CL, Gyawali S, Colbourne F (2006) Skilled reaching impairments follow intrastriatal hemorrhagic stroke in rats. Behav Brain Res 175(1):82-89. doi:10.1016/j.bbr.2006.08.001

Manley MS, Young SJ, Groves PM (1994) Compartmental organization of the peptide network in the human caudate nucleus. J Chem Neuroanat 7(3):191-201

Marques JM, Olsson IA (2010) Performance of juvenile mice in a reach-to-grasp task. J Neurosci Methods 193(1):82-85. doi:10. 1016/j.jneumeth.2010.08.016

Miklyaeva EI, Castaneda E, Whishaw IQ (1994) Skilled reaching deficits in unilateral dopamine-depleted rats: impairments in movement and posture and compensatory adjustments. J Neurosci 14(11 Pt 2):7148-7158

Mikula S, Parrish SK, Trimmer JS, Jones EG (2009) Complete 3D visualization of primate striosomes by KChIP1 immunostaining. J Comp Neurol 514(5):507-517. doi:10.1002/cne.22051

Mink JW (1996) The basal ganglia: focused selection and inhibition of competing motor programs. Prog Neurobiol 50(4):381-425

Olson L, Seiger A, Fuxe K (1972) Heterogeneity of striatal and limbic dopamine innervation: highly fluorescent islands in developing and adult rats. Brain Res 44(1):283-288

Penny GR, Wilson CJ, Kitai ST (1988) Relationship of the axonal and dendritic geometry of spiny projection neurons to the compartmental organization of the neostriatum. J Comp Neurol 269(2):275-289. doi:10.1002/cne.902690211

Pert CB, Kuhar MJ, Snyder SH (1976) Opiate receptor: autoradiographic localization in rat brain. Proc Natl Acad Sci USA 73(10):3729-3733 
Pimenta AF, Levitt P (2004) Characterization of the genomic structure of the mouse limbic system-associated membrane protein (Lsamp) gene. Genomics 83(5):790-801. doi:10.1016/j. ygeno.2003.11.013

Pisa M, Schranz JA (1988) Dissociable motor roles of the rat's striatum conform to a somatotopic model. Behav Neurosci 102(3):429-440

Prensa L, Parent A (2001) The nigrostriatal pathway in the rat: A single-axon study of the relationship between dorsal and ventral tier nigral neurons and the striosome/matrix striatal compartments. J Neurosci 21(18):7247-7260

Rabinowitz JE, Bowles DE, Faust SM, Ledford JG, Cunningham SE, Samulski RJ (2004) Cross-dressing the virion: the transcapsidation of adeno-associated virus serotypes functionally defines subgroups. J Virol 78(9):4421-4432

Ragsdale CW Jr, Graybiel AM (1991) Compartmental organization of the thalamostriatal connection in the cat. J Comp Neurol 311(1):134-167. doi:10.1002/cne.903110110

Redgrave P, Prescott TJ, Gurney K (1999) The basal ganglia: a vertebrate solution to the selection problem? Neuroscience 89(4):1009-1023

Schultz W (2007a) Behavioral dopamine signals. Trends Neurosci 30(5):203-210. doi:10.1016/j.tins.2007.03.007

Schultz W (2007b) Multiple dopamine functions at different time courses. Annu Rev Neurosci 30:259-288. doi:10.1146/annurev. neuro.28.061604.135722

Seiger A, Olson L (1973) Late prenatal ontogeny of central monoamine neurons in the rat: Fluorescence histochemical observations. Zeitschrift fur Anatomie und Entwicklungsgeschichte 140(3):281-318

Surace EM, Auricchio A (2008) Versatility of AAV vectors for retinal gene transfer. Vision Res 48(3):353-359. doi:10.1016/j.visres. 2007.07.027

Swain GP, Prociuk M, Bagel JH, O'Donnell P, Berger K, Drobatz K, Gurda BL, Haskins ME, Sands MS, Vite CH (2014) Adenoassociated virus serotypes 9 and rh10 mediate strong neuronal transduction of the dog brain. Gene Ther 21(1):28-36. doi:10. 1038/gt.2013.54

Tappe A, Kuner R (2006) Regulation of motor performance and striatal function by synaptic scaffolding proteins of the Homer1 family. Proc Natl Acad Sci USA 103(3):774-779. doi:10.1073/ pnas.0505900103

Tepper JM, Wilson CJ, Koos T (2008) Feedforward and feedback inhibition in neostriatal GABAergic spiny neurons. Brain Res Rev 58(2):272-281

Tokuno H, Chiken S, Kametani K, Moriizumi T (2002) Efferent projections from the striatal patch compartment: anterograde degeneration after selective ablation of neurons expressing muopioid receptor in rats. Neurosci Lett 332(1):5-8

Trytek ES, White IM, Schroeder DM, Heidenreich BA, Rebec GV (1996) Localization of motor- and nonmotor-related neurons within the matrix-striosome organization of rat striatum. Brain Res 707(2):221-227

Tunstall MJ, Oorschot DE, Kean A, Wickens JR (2002) Inhibitory interactions between spiny projection neurons in the rat striatum. J Neurophysiol 88(3):1263-1269

Uguru-Okorie DC, Arbuthnott GW (1981) Altered paw preference after unilateral 6-hydroxy-dopamine injections into lateral hypothalamus. Neuropsychologia 19(3):463-467

van der Kooy D, Fishell G (1987) Neuronal birthdate underlies the development of striatal compartments. Brain Res 401(1): $155-161$

Vergara-Aragon P, Gonzalez CL, Whishaw IQ (2003) A novel skilled-reaching impairment in paw supination on the "good" side of the hemi-Parkinson rat improved with rehabilitation. J Neurosci 23(2):579-586

Walker RH, Graybiel AM (1993) Dendritic arbors of spiny neurons in the primate striatum are directionally polarized. J Comp Neurol 337(4):629-639. doi:10.1002/cne.903370408

Walker RH, Arbuthnott GW, Baughman RW, Graybiel AM (1993) Dendritic domains of medium spiny neurons in the primate striatum: relationships to striosomal borders. J Comp Neurol 337(4):614-628. doi:10.1002/cne.903370407

Watabe-Uchida M, Zhu L, Ogawa SK, Vamanrao A, Uchida N (2012) Whole-brain mapping of direct inputs to midbrain dopamine neurons. Neuron 74(5):858-873. doi:10.1016/j.neuron.2012.03. 017

Whishaw IQ, O'Connor WT, Dunnett SB (1986) The contributions of motor cortex, nigrostriatal dopamine and caudate-putamen to skilled forelimb use in the rat. Brain 109(Pt 5):805-843

White NM, Hiroi N (1998) Preferential localization of self-stimulation sites in striosomes/patches in the rat striatum. Proc Natl Acad Sci USA 95(11):6486-6491

Wilson JS, Turner BH, Morrow GD, Hartman PJ (1987) MPTP produces a mosaic-like pattern of terminal degeneration in the caudate nucleus of dog. Brain Res 423(1-2):329-332

Xiao W, Chirmule N, Berta SC, McCullough B, Gao G, Wilson JM (1999) Gene therapy vectors based on adeno-associated virus type 1. J Virol 73(5):3994-4003

Yin HH, Knowlton BJ, Balleine BW (2006) Inactivation of dorsolateral striatum enhances sensitivity to changes in the actionoutcome contingency in instrumental conditioning. Behav Brain Res 166(2):189-196

Yung KK, Bolam JP, Smith AD, Hersch SM, Ciliax BJ, Levey AI (1995) Immunocytochemical localization of D1 and D2 dopamine receptors in the basal ganglia of the rat: light and electron microscopy. Neuroscience 65(3):709-730

Zhang F, Wang LP, Boyden ES, Deisseroth K (2006) Channelrhodopsin-2 and optical control of excitable cells. Nat Methods 3(10):785-792. doi:10.1038/nmeth936 